\title{
Study on 3D Pore Characteristics of Carbon Materials in HTGR by Micro-CT and HPMI Methods
}

\author{
Shengchao Ma, ${ }^{1}$ Zhenzhong Zhang, ${ }^{1}$ Kaiyue Shen, ${ }^{1}$ Xuedong He, ${ }^{1}$ Jun Li, ${ }^{2}$ \\ Huaqiang Yin $\mathbb{1}^{1},{ }^{1}$ Xingtuan Yang, ${ }^{1}$ and Shengyao Jiang ${ }^{1}$ \\ ${ }^{1}$ Institute of Nuclear and New Energy Technology, Collaborative Innovation Center of Advanced Nuclear Energy Technology, \\ Key Laboratory of Advanced Reactor Engineering and Safety of Ministry of Education, Tsinghua University, Beijing 100084, China \\ ${ }^{2}$ Nuclear Power Design and Research Sub-institute, Science and Technology on Reactor System Design Technology Laboratory, \\ Nuclear Power Institute of China, Chengdu 610213, China
}

Correspondence should be addressed to Huaqiang Yin; yinhuaqiang@tsinghua.edu.cn

Received 10 December 2018; Revised 7 March 2019; Accepted 24 March 2019; Published 2 May 2019

Academic Editor: Michael I. Ojovan

Copyright (C) 2019 Shengchao Ma et al. This is an open access article distributed under the Creative Commons Attribution License, which permits unrestricted use, distribution, and reproduction in any medium, provided the original work is properly cited.

\begin{abstract}
Many tons of porous carbon materials (including BC and IG-110) are contained in HTGR, which are serving as structural material and fuel matrix material. These materials would absorb moisture and other impurities when exposed to the environment, and these impurities (especially moisture) absorbed in the carbon material must be removed before the reactor operation to prevent corrosion reaction at high temperature (more than $500^{\circ} \mathrm{C}$ ). As the pore microscopic structure characteristic is the significant factor affecting the gas adsorption and flow in the porous materials, the detailed 3D pore structures of the carbon materials (BC and IG-110) in HTGR were studied by Micro-XCT and HPMI methods in this paper. These pore structure characteristics include pore geometry, pore size distribution, and pore throat connectivity. The test results show that the pore size distribution of $\mathrm{BC}$ material is wide, and the pore diameter is obviously larger than that of IG-110. Pore connections in BC show radial shape connections at some special points, and the pore connectivity in IG-110 is very complex and presents a huge complex 3D pore network.
\end{abstract}

\section{Introduction}

High-temperature gas-cooled reactors (HTGR) are valued by the nuclear industry departments of many countries due to their inherent safety, high-temperature process heat applications, and other outstanding characteristics $[1,2]$. And HTGR was considered as one of the most likely to be commercialized fourth-generation nuclear energy systems [3]. Carbon materials are widely used in primary loop systems of HTGR because of their good physical and chemical properties, such as good radiation stability, large neutron reflection cross section, and high-temperature resistance $[4,5]$. The pebble bed gas-cooled reactor is one of the typical HTGR, using a large amount of carbon materials as the structural material and the matrix material of the nuclear fuel, including boron-containing carbon material (BC) and isostatic pressure graphite IG-110. Tsinghua University was the earliest institute to research the HTGR in China. In 2000, it built a $10 \mathrm{MW}$ high-temperature gas-cooled experimental reactor HTR-10, which used more than 60 tons of graphite material [6]. Based on the success of HTR-10, Chinese government approved in 2004 to build a 200 MW HTGR demonstration power station (HTR-PM) in Rongcheng, Shandong Province, which used more than 1000 tons of carbon materials in its primary loop system [7-9].

The carbon materials in HTGR are typical porous materials which could absorb impurities, such as moisture $\left(\mathrm{H}_{2} \mathrm{O}\right)$, $\mathrm{O}_{2}$, and $\mathrm{CO}_{2}$, when they are exposed to the environment. And these impurities, especially $\mathrm{H}_{2} \mathrm{O}$ and $\mathrm{O}_{2}$, would corrode the carbon materials at high temperature (more than $500^{\circ} \mathrm{C}$ ), so they must be removed from the reactor core before the reactor operation $[10,11]$. The HTR-PM system has a limit of $2 \mathrm{~cm}^{3} / \mathrm{m}^{3}$ for the moisture content in the reactor core during the operation [12]. Therefore, dehumidification and purification operations are required before the reactor operation or after a water ingress accident. The dehumidification and 


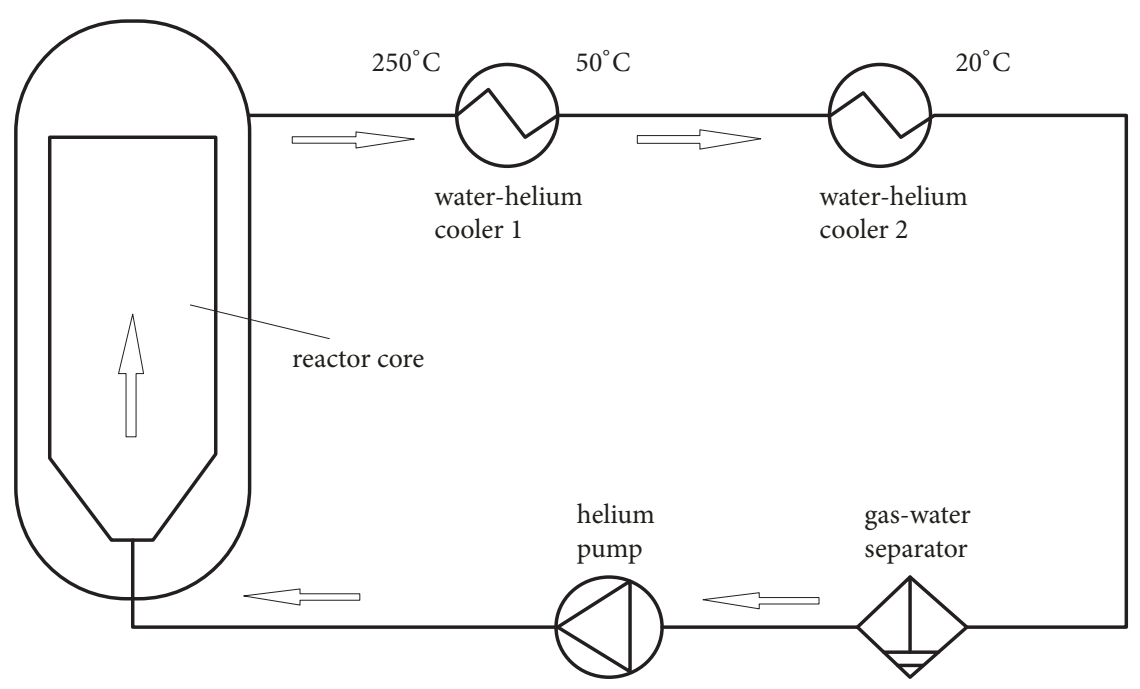

FIGURE 1: The dehumidification and purification system of HTR-PM.

purification system of HTR-PM was shown in Figure 1 [13]. For purification operation, a helium circulation is adopted to remove the moisture from the carbon materials in core. The helium gas is heated by the pump to $250^{\circ} \mathrm{C}$, and driving through the core and heating the carbon material. And then the moisture will diffuse from the carbon carried out of the core by helium gas. Then the helium gas back to the pump and complete the cycle after two stage water-helium coolers and gas-water separator.

There are studies that reported the oxidation behaviour of carbon material in HTGR, and some simulation models for the oxidation processes have been established [14-16]. Almost all of these studies have shown that the porosity and pore structure of the carbon materials have an important influence on the oxidation processes. The report of International Union of Pure and Applied Chemistry (IUPAC) about the gas absorption and desorption processes in porous materials has pointed out that the pore size and pore structure are the key factors in determining the shape of gas adsorption isotherm [17]. Regarding carbon materials (BC) in HTGR, Li Jun has reported that the pore size and pore structure have significant influences in moisture absorption and water molecules diffusion process $[18,19]$.

According to nuclear graphite IG-110, some reports have studied the pore structure characteristic with many different methods [20-22]. The scanning electron microscopy (SEM) technique was used to study the surface of the graphite, and the Brunauer-Emmett-Teller (BET) method was used to measure the specific surface area, the pore volume, and the average pore size of open pores based on the nitrogen adsorption and desorption isotherms. What is more, X-ray diffraction (XRD), Raman spectroscopy, and high resolution transmission electron microscope (HR-TEM) were used to understand the microstructure of nuclear graphite. However, Zheng's researches $[20,21]$ focused more on the morphology and pore size of graphite, but less on the connectivity of pore and the size of pore throat. Katie L. Jones provided some accurate and quantitative information on the entire ranges of pore sizes present in the highly complex pore network structure of nuclear graphite [22], through a multitechnique approach that includes $\mathrm{N}_{2}$ adsorption, SEM, and mercury intrusion methods.

In this paper, considering the important effects of pore characteristics on the gas diffusion and penetration processes in the porous carbon materials in HTGR, the detailed microscopic pore structure and the pore throat connectivity of BC and IG-110 were studied in detail. The scanning electron microscopy (SEM) technique and micro X-ray computer tomography (Micro-CT) were used to observe the pore morphology of material surface and the $3 \mathrm{D}$ pore characteristics, respectively. And the high-pressure mercury injection (HPMI) was used to measure the pore size distribution and size of pore throat.

\section{Materials and Measurements}

2.1. Materials. In order to study the mechanism of migration of moisture in the porous carbon materials in HTGR, the detailed structure of the pores must be clarified. The BC and IG-110 used in HTGR were studied in this paper, BC was provided by Fangda Carbon New Material Co., Ltd., China, and IG-110 was provided by Toyo Tanso Co., Ltd., Japan. The samples of these two materials are shown in Figure 2.

First, BC and IG-110 material samples are machined into cylinders with a diameter of $30 \mathrm{~mm}$ by turning lathe. Because the $\mathrm{BC}$ material is very hard, it needs to be processed with diamond bits. And then for HPMI test, the volume of the sample is required to be $2-5 \mathrm{~cm}^{3}$, so the cylinders with $30 \mathrm{~mm}$ diameter were processed into cylinders with $15 \mathrm{~mm}$ diameter and $15 \mathrm{~mm}$ height, just as seen in Figure 2(a). For SEM (scanning electron microscopy) observation, it is required that the thickness of the observed sample should not exceed $7 \mathrm{~mm}$, so a $3 \mathrm{~mm}$ thin sheet is cut from a cylinder with a diameter of $30 \mathrm{~mm}$ (seen points A and B in Figure 2(b)). After SEM scanning, a cylinder with $3 \mathrm{~mm}$ in diameter drilled from the wafer respectively was used for Micro-CT (micro X-ray 


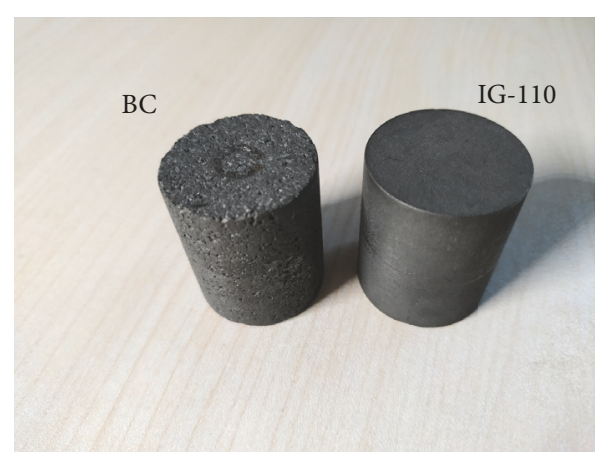

(a) The test samples of BC and IG-110 for HPMI test

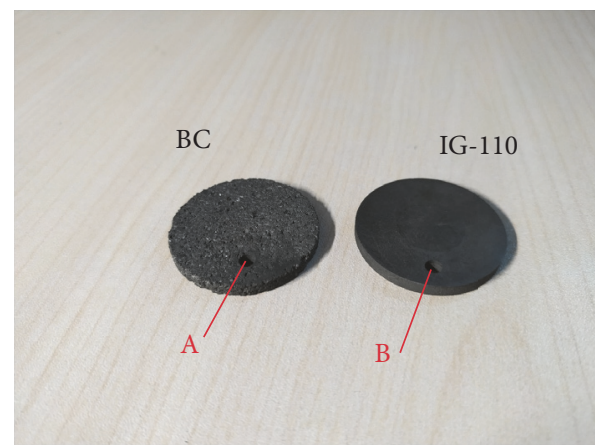

(b) The test samples of BC and IG-110 for SEM and Micro-CT tests. $(3 \mathrm{~mm}$ thin sheets are cut from a cylinder with diameter of $30 \mathrm{~mm}$ for Micro-CT test, seen points A and B in Figure 2(b))

Figure 2

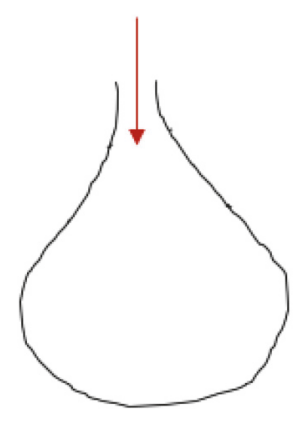

(a)

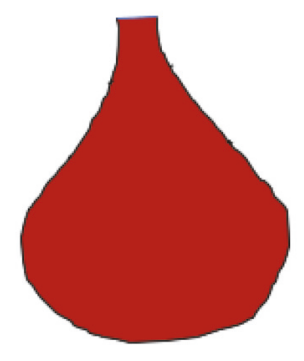

(b)

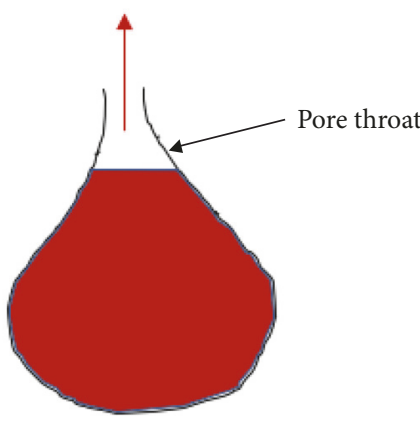

(c)

FIGURE 3: The simplification processes of HPMI test. The pore is simplified to ink bottle shape, the image (a) represents the empty pore, image (b) is the pore filled with mercury, and image (c) represents that some mercury remains in the pore inside after the extrusion process.

computer tomography) detection (Figure 2(b), point A and B).

2.2. Measurements. Recently, scanning electron microscopy (SEM) and micro X-ray computer tomography (Micro-CT) have become the most commonly methods to study the surface morphology and internal structure of porous materials [23]. However, it is difficult to get the size information of the pore connection channel (pore throat) from the 3D images obtained from Micro-CT scanning. The HPMI method may answer this question; numerous investigations have proven that high-pressure mercury injection (HPMI) is a powerful method for detecting pore size distributions [24-27]. Several computer models have treated porous materials as a network of empty pores interconnected by a network of small channels (pore throats) [28]. One of the inferences from the network models is that the shapes of mercury intrusion and extrusion curves may reflect the size of pores and throats. The shape of mercury intrusion curve could be related to pore throats, while the extrusion curve reflects the shape of cavities (pores). The throat/pore ratio $R_{T P}$ is calculated as follows:

$$
R_{T P, i}=\left(\frac{D_{T}}{D_{P}}\right)_{i}
$$

where $D(\mathrm{~mm})$ is the throat and pore diameter, the subscripts $T$ and $P$ refer to throat of pore and pore cavity, respectively.

In HPMI test, the simplification processes of mercury entering into the pore and extruding from the pore are shown in Figure 3. Mercury enters the pore under the high pressure, and with the increasing of pressure the pore is until filled with mercury. Then the pressure decreases, mercury in the pore throat first extrudes from the pore under the action of capillary pressure, while the mercury in the pore inside cannot be completely extruded. Therefore, $R_{T P}$ can be expressed by the volume ratio of mercury in the pore throat and pore inside. And when the intrusion and extrusion contact angles between mercury and material are assumed as constant, $R_{T P}$ is simply given by the ratio of extrusion mercury to intrusion mercury at given $\emptyset_{i}\left(\emptyset_{i}=V_{I} / V_{M}\right)$ :

$$
R_{T P}=\frac{\left(V_{M}-V_{E}\right)}{V_{M}}
$$

in which $V_{I}\left(\mathrm{~mm}^{3}\right)$ is the mercury volume intruded at any given pressure, $V_{M}$ is the mercury volume intruded at the maximum experimental pressure, and $V_{E}$ is the mercury volume left in materials during the mercury extrusion progress. 


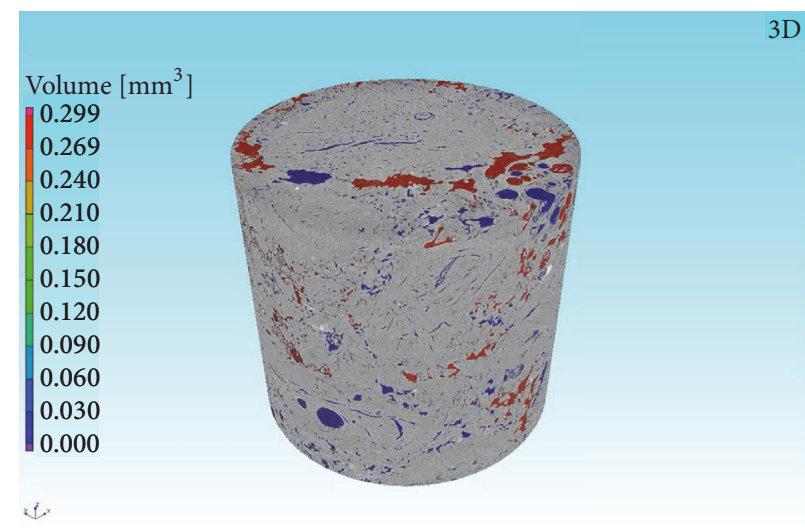

(a) 3D images of pore structures of $\mathrm{BC}$ measured by Micro-CT

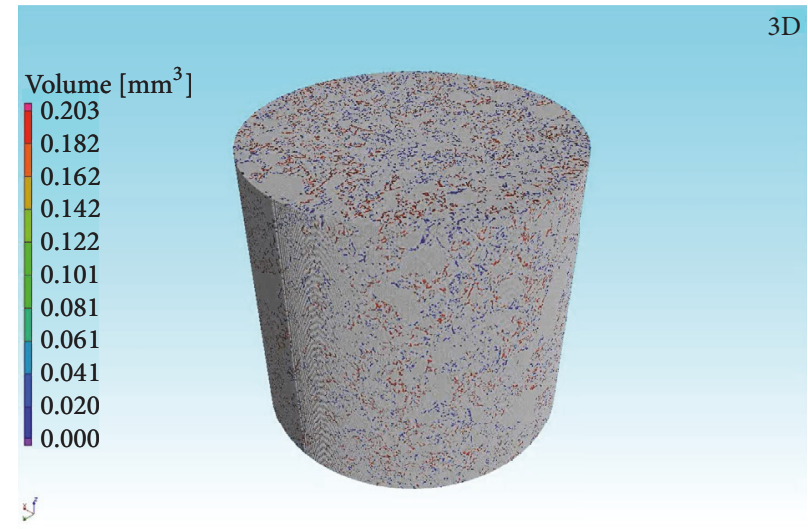

(b) 3D images of pore structures of IG-110 measured by Micro-CT

FigURE 4

\section{Test Results and Discussion}

3.1. 3D Pore Structure Analysis. The Nanotom M Micro-CT (GE, America) was used, the size of BC and IG-110 samples was $\mathrm{D} 3 \mathrm{~mm} * \mathrm{H} 3 \mathrm{~mm}$, and the resolution was set as $0.9 \mu \mathrm{m}$. The three-dimensional distributions of pores of BC and IG110 are shown in Figure 4. As can be seen, the pore volume of $\mathrm{BC}$ is relatively larger and the pore structure is very irregular, and the maximal pore volume given by Micro-CT is about $0.3 \mathrm{~mm}^{3}$. On the contrary, the matrix of IG-110 is relatively denser, the pores are widely distributed in the matrix, and the pores volume of IG-110 is not as big BC, whose maximal pore volume is about $0.2 \mathrm{~mm}^{3}$. From Figure 4(b), it can be seen that the 3D images of IG-110 samples obtained by Micro-CT scanning are in good agreement with Guiqiu Zheng's research results $[27,28]$.

The pore distributions on the cross section of these two samples are shown in Figure 5. It can be clearly seen from Figure 5(a) that the pore structure inside BC is very irregular, and there are obvious cracks at locations A, B, and C. But there are no obvious cracks inside the IG-110, and the pores in IG-110 are uniformly distributed.

Three slice pairs from 3D Micro-CT images of BC and IG-110 along the core axis were identified, which are shown in Figure 6. The pores distribution images exhibited by the different slice pairs of the $\mathrm{BC}$ material are quite different, which indicates that the pore size of $\mathrm{BC}$ is big and the pore is relatively dispersive in three-dimensional space. Conversely, the images of the IG-110 slices at different locations are not significantly different, indicating that the pore volume in the IG-110 material is small and the distribution is relatively uniform.

In order to verify the Micro-CT test results, the surface of BC and IG was observed using SEM technique (Zeiss Field Emission SEM, model Merlin Compact, Germany), and the results of the observation are shown in Figure 7. It can be intuitively observed that the surface morphology of BC is very complicated, covered with large matrix particles, and widely distributed with large-sized pores and holes. The irregular surface morphology of $\mathrm{BC}$ is just like the complex mountains of the earth surface. In contrast, the surface of IG-110 is much smoother than that of BC, with only a few small-size defects and no visible cracks and holes.

3.2. Porosity and Pore Size Analysis. Porosity and the pore size are important parameters of porous material, these two parameters are pivotal to explain the macroscopic properties of the material. In this paper, HPMI method (AutoPore IV 9500, Germany) was used to analyze the porosity and the pore size distribution of $\mathrm{BC}$ and IG-110; this method is to press liquid mercury into the pore of sample under high pressure, and the volume of samples is in the range of $2 \mathrm{~cm}^{3}-5 \mathrm{~cm}^{3}$. The porosity is calculated by the function as follows:

$$
\text { porosity }=\frac{V_{M}}{V_{S}} \times 100 \%
$$

in which $V_{M}$ is the maximum volume of mercury intrusion, and $V_{S}$ is the apparent volume of the sample. Some HPMI test parameters are shown in Table 1.

The test results of BC and IG-110 measured by HPMI are shown in Table 2.

As seen from Table 2, the porosity and total pore area of IG-110 are obviously larger than that of BC, but the median pore diameter of $\mathrm{BC}$ is almost three times that of IG-110, which can be seen from the Micro-CT and SEM test results. The mercury intrusion curves of HPMI test are shown in Figure 8. The mercury intrusion volume of IG-110 is larger than that of $\mathrm{BC}$ under same pressure, so the porosity of IG-110 calculated by Function (4) is larger than that of BC.

The pore size (radius) has a strong relationship with the capillary pressure, which is calculated by the following function:

$$
P_{c}=\frac{2 \sigma \cos \theta}{r}
$$

where $P c$ is the capillary pressure $(\mathrm{kPa}), r$ is the pore radius $(\mathrm{nm}), \sigma$ is the surface tension, and $\theta$ is the contact angle $\left({ }^{\circ}\right)$. 


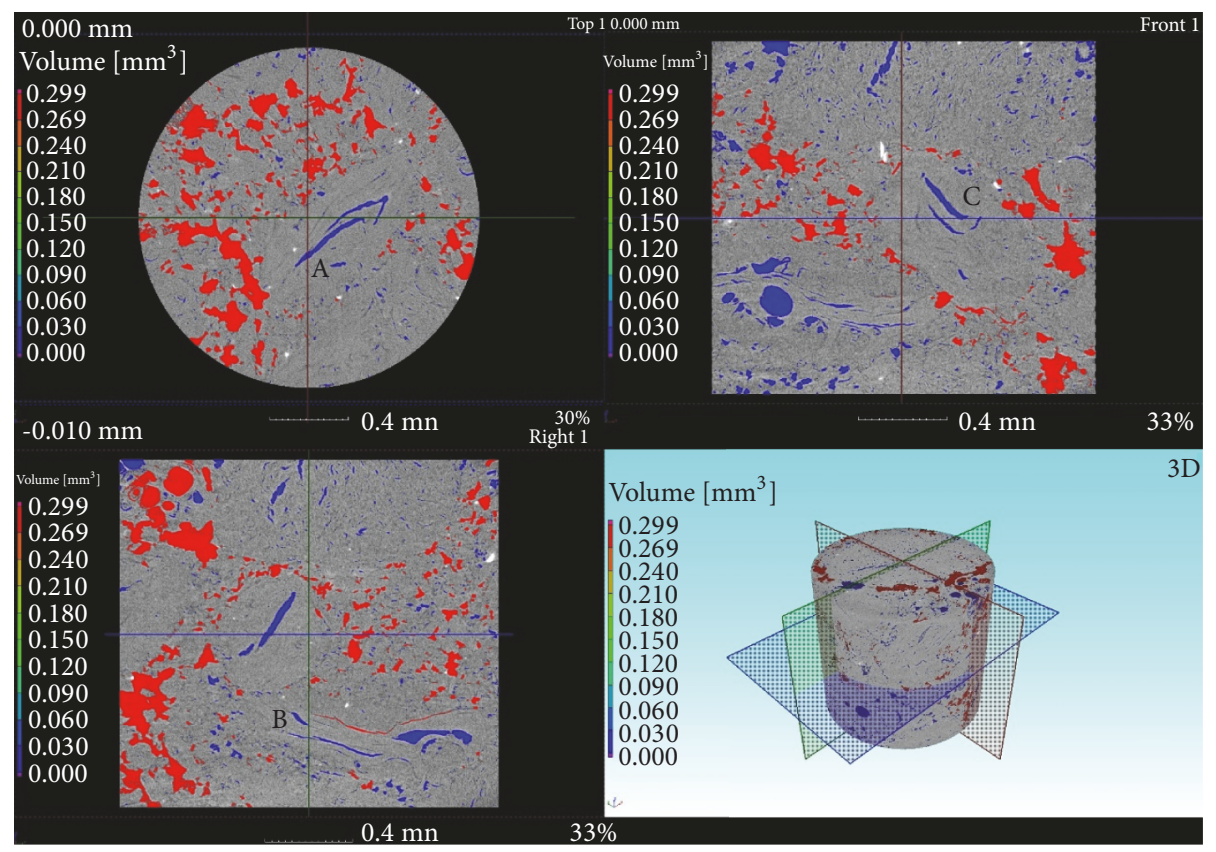

(a) $\mathrm{BC}$

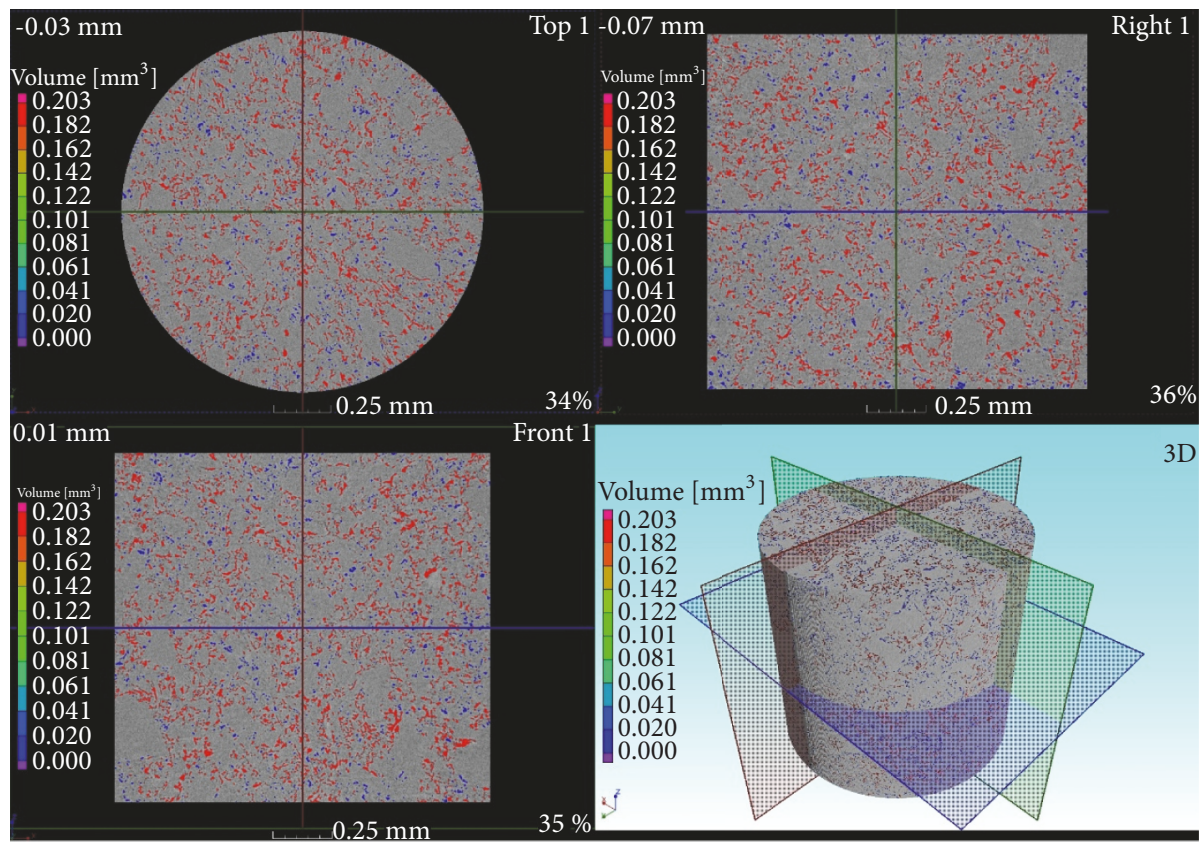

(b) IG-110

Figure 5: The cross-sectional images of BC and IG-110. The cross-sectional images are taken from the previous, left and upper directions respectively, and the positions of the cross-sectional images are shown in the three-dimensional model of the lower right corner in the figure.

Mercury can be pressed into the pore only when the external pressure is greater than the capillary pressure in the pore. From Function (4), when the pressure is low, mercury just enter the large pores. As the pressure increases, mercury can enter the smaller pore until all the pores are filled. When the pore is fully filled by mercury, the apparent pore volume of the sample is obtained by the volume of the injected mercury. Then the pressure gradually decreases, and under the action of capillary pressure in the pores, the mercury injected into the material exits from the interconnected pore throat. However, the mercury in the pores cannot completely exit, and this is the main reason for the difference in intrusion and extrusion mercury curve.

The pore diameter can be calculated according to Function (4) and the relationship curve between mercury volume and pressure. The pore volume and pore area distribution 

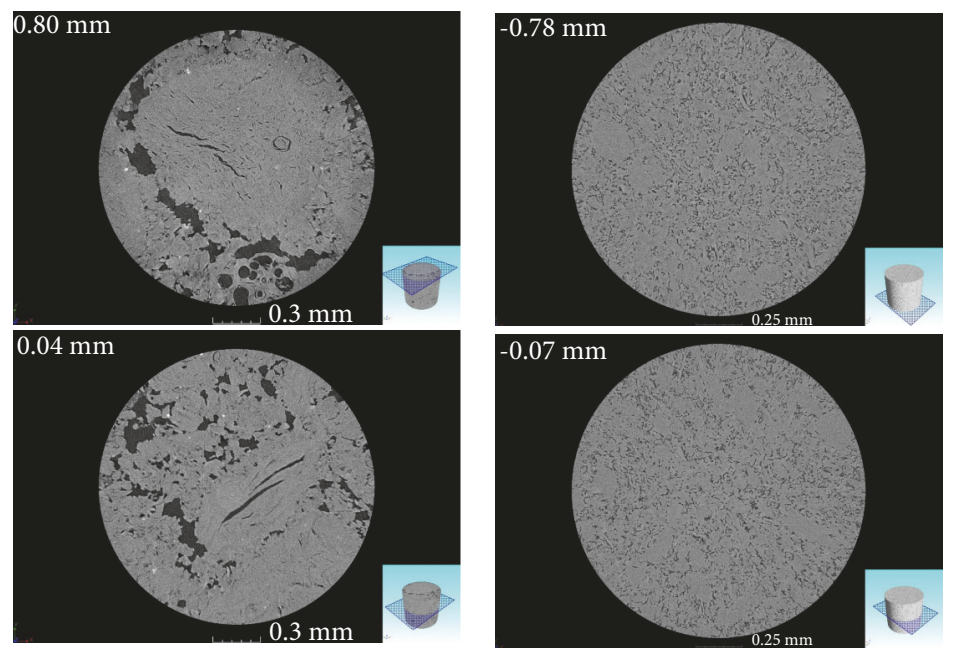

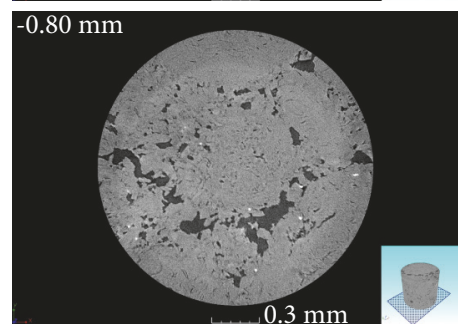

(a) $\mathrm{BC}$

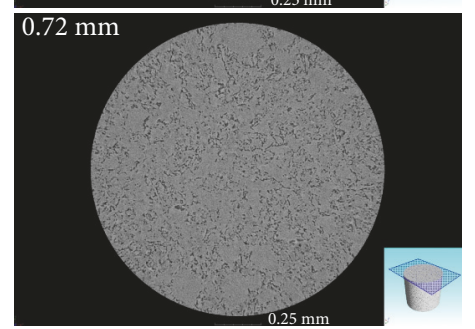

(b) IG-110

FIGURE 6: Slice images of different positions of BC and IG-110. Three slice pairs from 3D Micro-CT images of BC and IG-110 were identified along the core axis, and the position of the slice is shown in the three-dimensional model of the lower right corner in the figure.

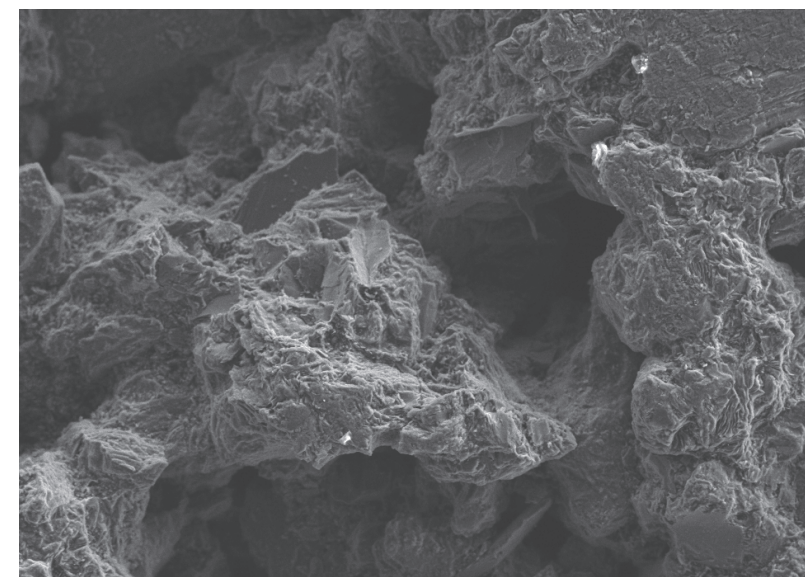

(a) The SEM test image of BC

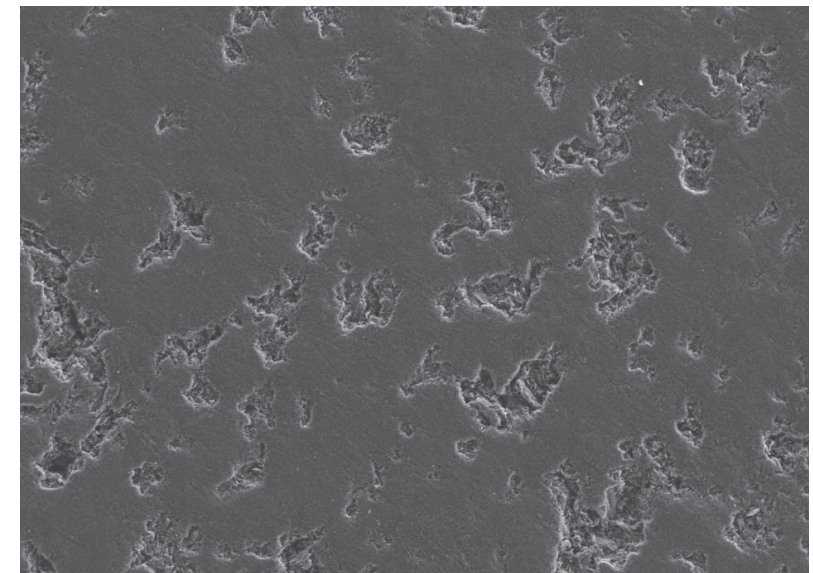

(b) The SEM test image of IG-110

Figure 7

curves of BC and IG-110 measured by HPMI test are shown in Figure 9, and the abscissa is the logarithm of pore diameter $\mathrm{D}(\mathrm{nm})$.

From the pore volume distribution curve of $\mathrm{BC}$ in Figure 9(a), it can be seen that the micropore size of $\mathrm{BC}$ is the main part of the total pore volume, while the proportion of nanopore size is relatively smaller. The pore size is mainly distributed in three intervals: $2 \mathrm{~nm}-30 \mathrm{~nm}$ (20.6\%), $0.1 \mu \mathrm{m}$
- $4 \mu \mathrm{m}$ (25.68\%), and $4 \mu \mathrm{m}$ - $60 \mu \mathrm{m}$ (40.42\%). The pore size and distribution of $\mathrm{BC}$ are in well agreement with the images of pore morphology obtained by Micro-CT and SEM in Section 3.1. From the pore area distribution curve, it can be found that the most important contribution to the pore surface area is nanoscale pore, with pore diameter less than $10 \mathrm{~nm}$. Very obvious peak can be seen from the pore volume distribution curve of IG-110 in Figure 9(b), which indicates 
TABLE 1: HPMI test parameters.

\begin{tabular}{lcc}
\hline Parameter & Value & Unit \\
\hline Contact angle with BC & 130.0 & degree $\left(^{\circ}\right)$ \\
Contact angle with IG-110 & 130.0 & degree $\left(^{\circ}\right)$ \\
Hg surface tension & 485.0 & dynes $/ \mathrm{cm}^{\circ}$ \\
Hg density & 13.5364 & $\mathrm{~g} / \mathrm{ml}$ \\
Equilibration time & 10 & $\mathrm{~s}$ \\
Initial pressure & 1.379 & $\mathrm{kPa}$ \\
Maximum pressure & 413700 & $\mathrm{kPa}$ \\
Evacuation pressure & 127.56 & $\mathrm{kPa}$ \\
\hline
\end{tabular}

TABLE 2: The test results of BC and IG-110.

\begin{tabular}{lcccc}
\hline Parameter & BC & IG-110 & \\
\hline Sample Size & $\mathrm{D} \times \mathrm{H}(5 \times 5)$ & $\mathrm{D} \times \mathrm{H}(5 \times 5)$ & $\mathrm{Unit}$ \\
Weight & 4.4410 & 4.6457 & $\mathrm{~mm}$ \\
Total Intrusion Volume & 0.0911 & 0.1234 & $\mathrm{~g}$ \\
Total Pore Area & 13.777 & 20.856 & $\mathrm{ml} / \mathrm{g}$ \\
Median Pore Diameter (volume) & 7311.4 & 2063.9 & $\mathrm{~m} 2 / \mathrm{g}$ \\
Average Pore Diameter & 26.5 & 23.7 & $\mathrm{~nm}$ \\
Apparent (skeletal) Density & 1.9936 & 2.2073 & $\mathrm{~nm}$ \\
Porosity & 15.3707 & 21.4010 & $\mathrm{~g} / \mathrm{ml}$ \\
\hline
\end{tabular}

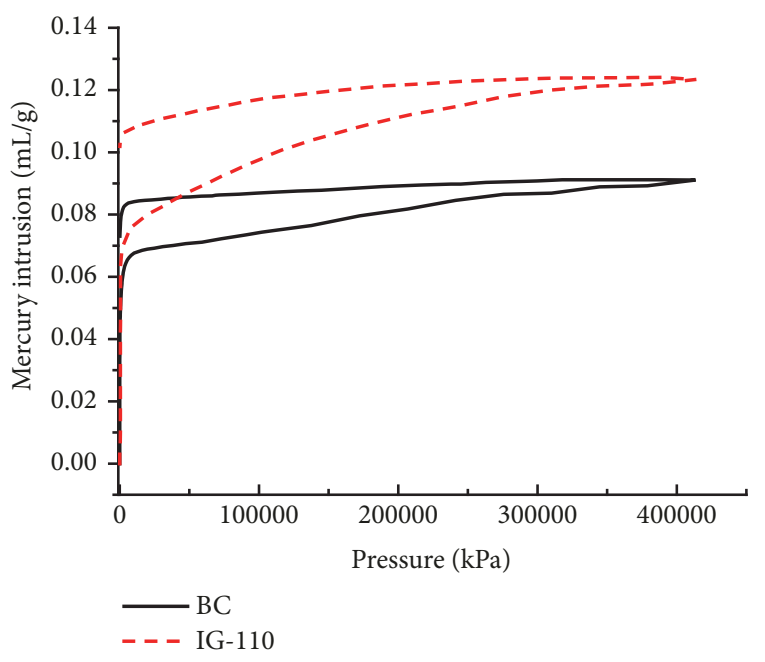

FIGURE 8: The mercury intrusion and extrusion curves of $\mathrm{BC}$ and IG-110. The mercury intrusion volume of IG-110 is larger than that of BC under same pressure.

that the pore size is strongly concentrated in the small range of $1.5 \mu \mathrm{m}-3.0 \mu \mathrm{m}$ (49.34\%). Nevertheless, within the range of less than $28 \mathrm{~nm}$, a considerable proportion of the voids still exists, accounting for $30 \%$. According to the pore area distribution curve, nanoscale pores are the most important contributor to the total pore surface area, and the pore size is less than $10 \mathrm{~nm}$, which is consistent with $\mathrm{BC}$.

3.3. Pore Throat Connectivity Analysis. The 3D data of pores structure has been obtained from Micro-CT method, and then the Avizo Software (an advanced 3D visualization and analysis application software) was used to the pore throat connectivity analysis. In view that the data of the samples with a size of $\mathrm{D} 3 \mathrm{~mm} * \mathrm{H} 3 \mathrm{~mm}$ obtained by Micro-CT scanning is too large, a cube data with a side length of $0.35 \mathrm{~mm}$ was selected therefrom for the pore throat analysis.

The pore throat interconnected image of $\mathrm{BC}$ is shown in Figure 9. The pore connectivity in BC is few and scattered, and the shape of the interconnected pores is very complicated. And the connection between the upper and lower sides strongly depended on some certain points, such as the point $\mathrm{A}$ in Figure 10. In these locations, the transport pores appear to radial pattern.

It can be found in Figure 11 that the pore throat connectivity of IG-110 is much more complicated than that of BC. The number of pore throats in the IG-110 sample is very large, and they interconnect with their neighbors thus forming a huge complex 3D pore network. However, from the analysis of the $3 \mathrm{D}$ pore connective images obtained by Micro-CT scanning, we can conclude that the pore connectivity in IG-110 is more complicated than that of $\mathrm{BC}$, but the pore throat size cannot be obtained.

Then, the HPMI test was used in this paper, and the intrusion and extrusion curves of BC and IG-110 by HPMI test are shown in Figure 9. It can be seen that IG-110 has a larger mercury intrusion than BC under same pressure, and the difference between the curves of mercury intrusion and extrusion of IG-110 is larger than that of BC, which indicates that a larger proportion of mercury in $\mathrm{BC}$ remains in the pore cavities during the process of mercury extrusion.

The pore throat/pore ratio $R_{T P}$ can be calculated from Function (3), and the $R_{T P}$ curves of BC and IG-110 in extrusion process are presented in Figure 12. From this figure, we can see that the $R_{T P}$ curves of $\mathrm{BC}$ and IG-110 changed 


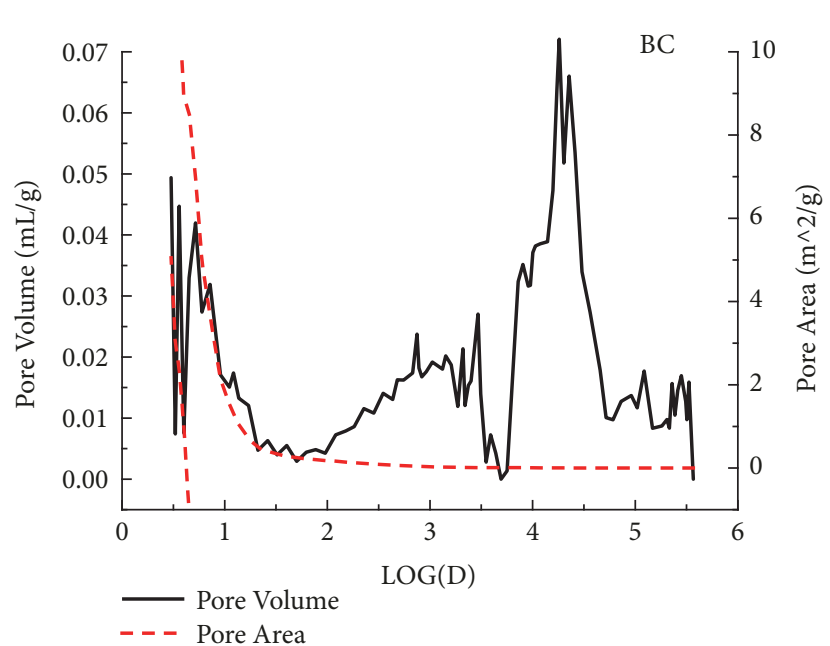

(a) $\mathrm{BC}$

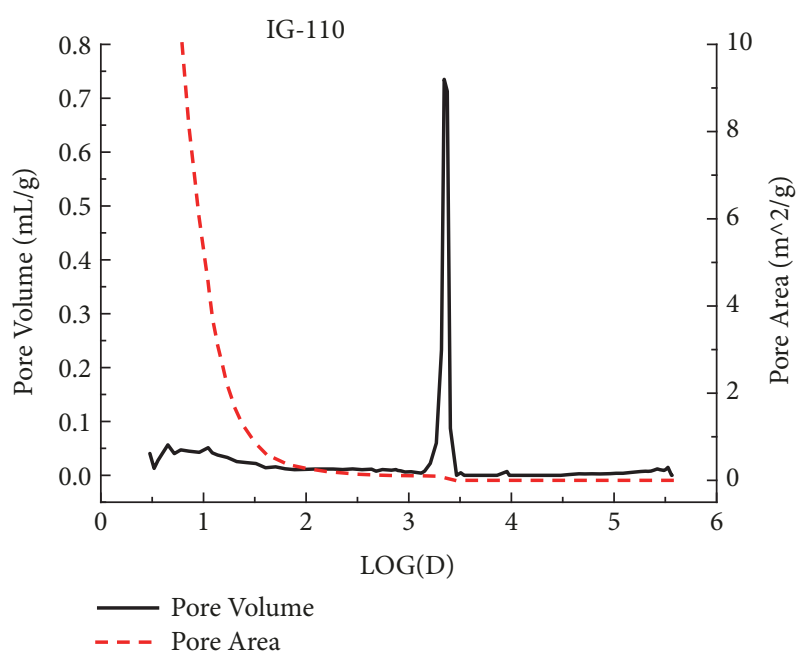

(b) IG-110

FIgURE 9: The pore size distribution of BC and IG-110 by HPMI. The abscissa is the logarithm of pore diameter D (nm), the pore area curves of BC and IG-110 is similar, and the pore volume cure of BC has many peaks, while the curve of IG-110 has only one very obvious peak.

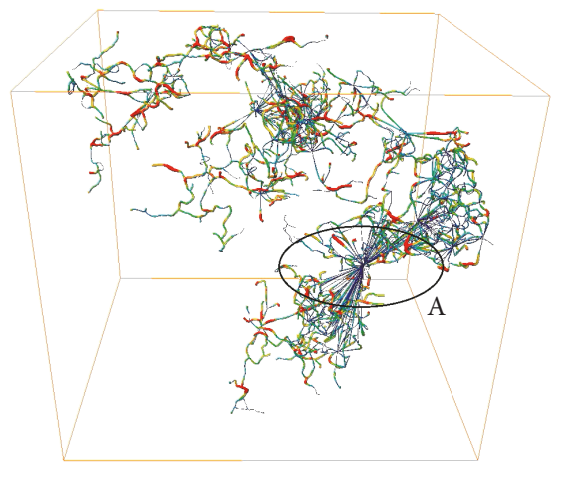

(a)

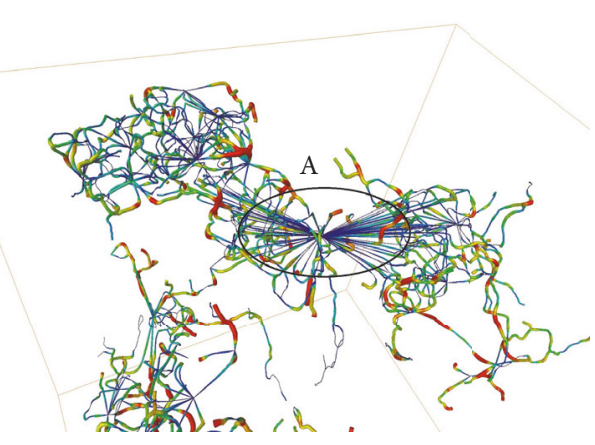

(b)

FIGURE 10: The pore throat connectivity of BC. Figure $10(\mathrm{a})$ is the $3 \mathrm{D}$ image of the $0.35 \mathrm{~mm}$ length cube sample of BC, and Figure $10(\mathrm{~b})$ is an enlargement of point A in Figure 10(a).

slowly in the early stage of the mercury extrusion process (less than $13000 \mathrm{kPa}$ ), and the difference between the $R_{T P}$ values of $\mathrm{BC}$ and IG-110 was small. When the pressure drops to about $13000 \mathrm{kPa}$, the slope of $R_{T P}$ curve of IG-110 exceeds BC, while the $R_{T P}$ curve of $\mathrm{BC}$ keeps a slower change before the pressure drops to near $0 \mathrm{kPa}$. And the $R_{T P}$ of $\mathrm{BC}$ is larger than that of IG-110 at the end of mercury extrusion.

The analysis of the intrusion and extrusion mercury curves and $R_{T P}$ curves in Figure 12 shows that the $R_{T P}$ of $\mathrm{BC}$ is larger than that of IG-110 at the end of mercury extrusion, which indicates that the mercury is easier to extrude from BC. At the same time, according to the analysis of pore size distribution in Section 3.2, the pore size of $\mathrm{BC}$ is larger than that of IG-110, and the distribution of pore diameter is wider than that of IG-110. It can be concluded that although the pore connected channel of BC material is not as complex as IG110 , but the size of pore connection (pore throat) is larger, so the connectivity of BC material is better than IG-110 in general.

\section{Conclusions}

In this paper, the 3D pore structure characteristics, including porosity, pore size distribution, and pore throat connectivity, of carbon materials BC and IG-110 in HTGR were studied. The advantages and disadvantages of Micro-CT and HPMI in measuring pore size were analyzed. The following conclusions can be drawn.

(1) The pore structure inside the $\mathrm{BC}$ is very irregular; some of the pores have strong ductility in three-dimensional space. On the contrary, there are no obvious cracks inside the IG-110, and the pores are uniformly distributed.

(2) Through the analysis of pore structure in Section 3.1, the pore diameter distribution measured by HPMI method is considered in much more agreement with the real situation of materials. Although the pore size of IG-110 is not large as $\mathrm{BC}$, the porosity of IG-110 is larger than that of BC obviously.

(3) The pore size of $\mathrm{BC}$ is mainly distributed in three intervals: $2 \mathrm{~nm}-30 \mathrm{~nm}(20.6 \%), 0.1 \mu \mathrm{m}-4 \mu \mathrm{m}(25.68 \%)$, and 


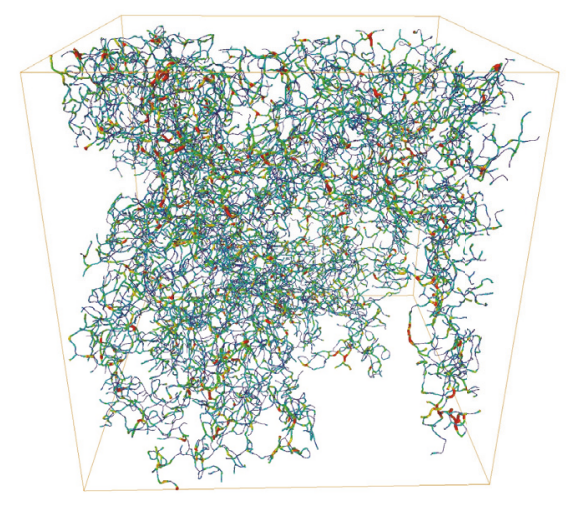

FIGURE 11: The pore throat connectivity of IG-110.

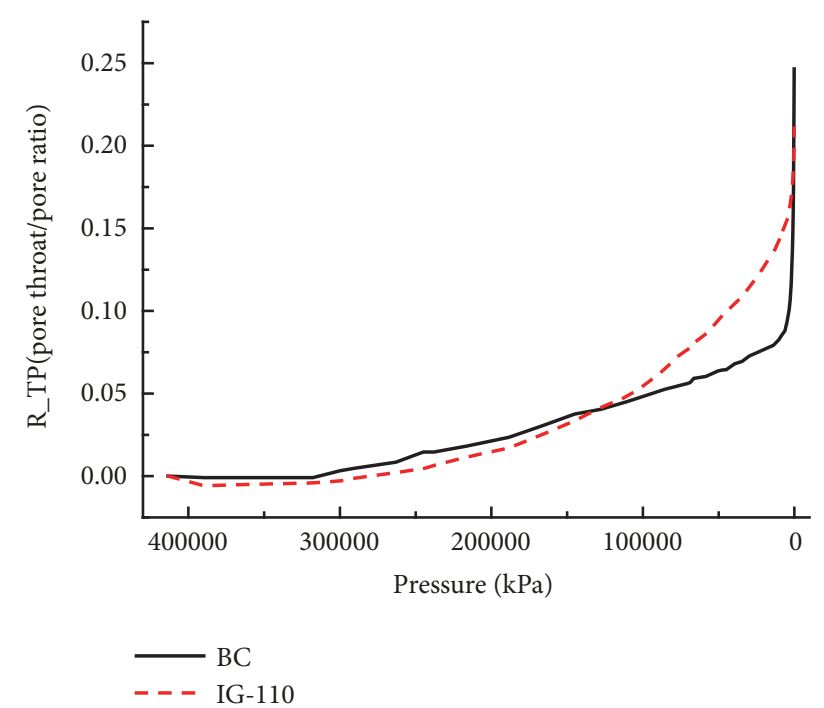

FIgURE 12: The $R_{T P}$ curves of BC and IG-110 in mercury extrusion process.

$4 \mu \mathrm{m}-60 \mu \mathrm{m}(40.42 \%)$. The pore size of IG-110 is strongly concentrated in the small range of $1.5 \mu \mathrm{m}-3.0 \mu \mathrm{m}(49.34 \%)$, but a considerable proportion of the pores still exist within the range of less than $28 \mathrm{~nm}$, accounting for $30 \%$. Nanoscale pore is the most important contributor to the pore surface area in BC and IG-110, and the pore size is less than $10 \mathrm{~nm}$.

(4) The pore interconnected of BC is not as complex as IG-110, but the size of pore and pore throat are larger, so the connectivity of BC material is better than IG-110 in general. In some special locations, the pore interconnection of BC appears in radial shape; however, there is no obvious phenomenon of pore connectivity in IG-110, and its pore interconnection presents just like a complex spider web.

\section{Data Availability}

The data used to support the findings of this study are included within the article.

\section{Conflicts of Interest}

The authors declare that there are no conflicts of interest regarding the publication of this paper.

\section{Acknowledgments}

This work was supported by the National Natural Science Foundation of China (NSFC) (Grant No. 11875176) and the Chinese National S\&T Major Project (Grant No. ZX06901).

\section{References}

[1] G. H. Lohnert, "Technical design features and essential safetyrelated properties of the HTR-module," Nuclear Engineering and Design, vol. 121, no. 2, pp. 259-275, 1990.

[2] T. Takeda and M. Hishida, "Study on the passive safe technology for the prevention of air ingress during the primary-pipe rupture accident of HTGR," Nuclear Engineering and Design, vol. 200, no. 1, pp. 251-259, 2000.

[3] J. I. A. Xiao-bo, "Discussion on generation-IV nuclear energy guarantee system," China Nuclear Power, vol. 3, p. 017, 2010.

[4] D. V. Ragone, W. V. Goeddel, and L. R. Zumwalt, "Graphitematrix nuclear fuel systems for the peach bottom HTGR," Tech. Rep. GA-4002, General Atomic Div. General Dynamics Corp., San Diego, Calif, USA, 1963.

[5] K. Natesan, A. Purohit, and S. W. Tam, Materials behavior in HTGR environments, Division of Engineering Technology, Office of Nuclear Regulatory Research, US Nuclear Regulatory Commission, 2003.

[6] Z. Zhang, J. Liu, S. He, Z. Zhang, and S. Yu, "Structural design of ceramic internals of HTR-10," Nuclear Engineering and Design, vol. 218, no. 1-3, pp. 123-136, 2002.

[7] X. Zhou, Y. Tang, Z. Lu, J. Zhang, and B. Liu, "Nuclear graphite for high temperature gas-cooled reactors," New Carbon Materials, vol. 32, no. 3, pp. 193-204, 2017.

[8] Z. Zhang, Z. Wu, Y. Sun, and F. Li, "Design aspects of the Chinese modular high-temperature gas-cooled reactor HTRPM," Nuclear Engineering and Design, vol. 236, no. 5-6, pp. 485490, 2006.

[9] Z. Zhang and S. Yu, "Future HTGR developments in China after the criticality of the HTR-10," Nuclear Engineering and Design, vol. 218, no. 1-3, pp. 249-257, 2002.

[10] H. Kawakami, "Air oxidation behavior of carbon and graphite materials for HTGR," TANSO, vol. 1986, no. 124, pp. 26-33, 1986.

[11] E. S. Kim, C. H. Oh, and H. C. No, "Experimental study and model development on the moisture effect for nuclear graphite oxidation," Nuclear Technology, vol. 164, no. 2, pp. 278-285, 2008.

[12] X.-L. Yu, X.-W. Luo, and S.-Y. Yu, "Simulation of oxidation in HTR-10 core," Nuclear Power Engineering, vol. 31, no. 2, pp. 8184, 2010.

[13] J. Y. Dou and H. Q. Yin, "Preliminary investigation into the dehumidifcation model of HTR-PM initial core," in Proceedings of the 14th National Symposium on Reactor Termal Fluid, Beijing, China, 2015.

[14] B. T. Kelly, B. J. Marsden, and K. Hall, "Irradiation damage in graphite due to fast neutrons in fission and fusion systems," IAEA Tecdoc, no. 1154, 2000.

[15] C. I. Contescu, R. W. Mee, Y. J. Lee et al., "Beyond the classical kinetic model for chronic graphite oxidation by moisture in 
high temperature gas-cooled reactors," Carbon, vol. 127, pp. 158169, 2018.

[16] W. Chengqi, X. Sun, R. N. Christensen, and S. Shi, "Numerical simulation of chronic moisture graphite oxidation for MHTGR," Transactions of the American Nuclear Society, vol. 118, pp. 17-21, 2018/.

[17] M. Thommes, K. Kaneko, A. V. Neimark et al., "Physisorption of gases, with special reference to the evaluation of surface area and pore size distribution (IUPAC Technical Report)," Pure \& Applied Chemistry, vol. 38, no. 1, pp. 25-25, 2015.

[18] L. Jun, Y. Huaqiang, Y. Xingtuan, and J. Shengyao, "Analysis on Moisture transfer behavior in dehumidifying process of low moisture content graphite," in Proceedings of the 2017 25th International Conference on Nuclear Engineering, Shanghai, China, 2017.

[19] J. Li, Z. Zhang, Y. Meng et al., "Moisture transfer model and simulation for dehumidification of HTGR core," Science and Technology of Nuclear Installations, vol. 2018, Article ID 4163914, 8 pages, 2018.

[20] G. Q. Zheng, P. Xu, K. Sridharan, and T. R. Allen, "Pore structure analysis of nuclear graphites IG-110 and NBG-18," in Advances in Materials Science for Environmental and Nuclear Technology II, vol. 227, John Wiley \& Sons, Inc., 2011.

[21] G. Zheng, P. Xu, K. Sridharan, and T. Allen, "Characterization of structural defects in nuclear graphite IG-110 and NBG-18," Journal of Nuclear Materials, vol. 446, no. 1-3, pp. 193-199, 2014.

[22] K. L. Jones, G. M. Laudone, and G. P. Matthews, "A multitechnique experimental and modelling study of the porous structure of IG-110 and IG-430 nuclear graphite," Carbon, vol. 128, pp. 1-11, 2018.

[23] H. Gao and H. A. Li, "Pore structure characterization, permeability evaluation and enhanced gas recovery techniques of tight gas sandstones," Journal of Natural Gas Science and Engineering, vol. 28, pp. 536-547, 2016.

[24] K. K. Unger, F. Rodríguez-Reinoso, J. Rouquerol, and K. Sing, Eds., Characterization of Porous Solids II, vol. 62, Elsevier, 1991.

[25] F. A. L. Dullien, Porous Media: Fluid Transport and Pore Structure, Academic Press, 2012.

[26] P. Shen, K. Li, and F. Jia, "Quantitative description for the heterogeneity of pore structure by using mercury capillary pressure curves," in Proceedings of the International Meeting on Petroleum Engineering. Part 1 (of 2), pp. 447-456, November 1995.

[27] Z. M. Sun, X. C. Lu, X. C. Jia, Y. S. Bai, and W. X. Hu, "Optimization of mercury intrusion capillary pressure measurement for characterizing the pore structure of tight rocks," Journal of Nanoscience and Nanotechnology, vol. 17, no. 9, pp. 6242-6251, 2017.

[28] C. A. Léon y León, "New perspectives in mercury porosimetry," Advances in Colloid and Interface Science, vol. 76-77, pp. 341-372, 1998. 

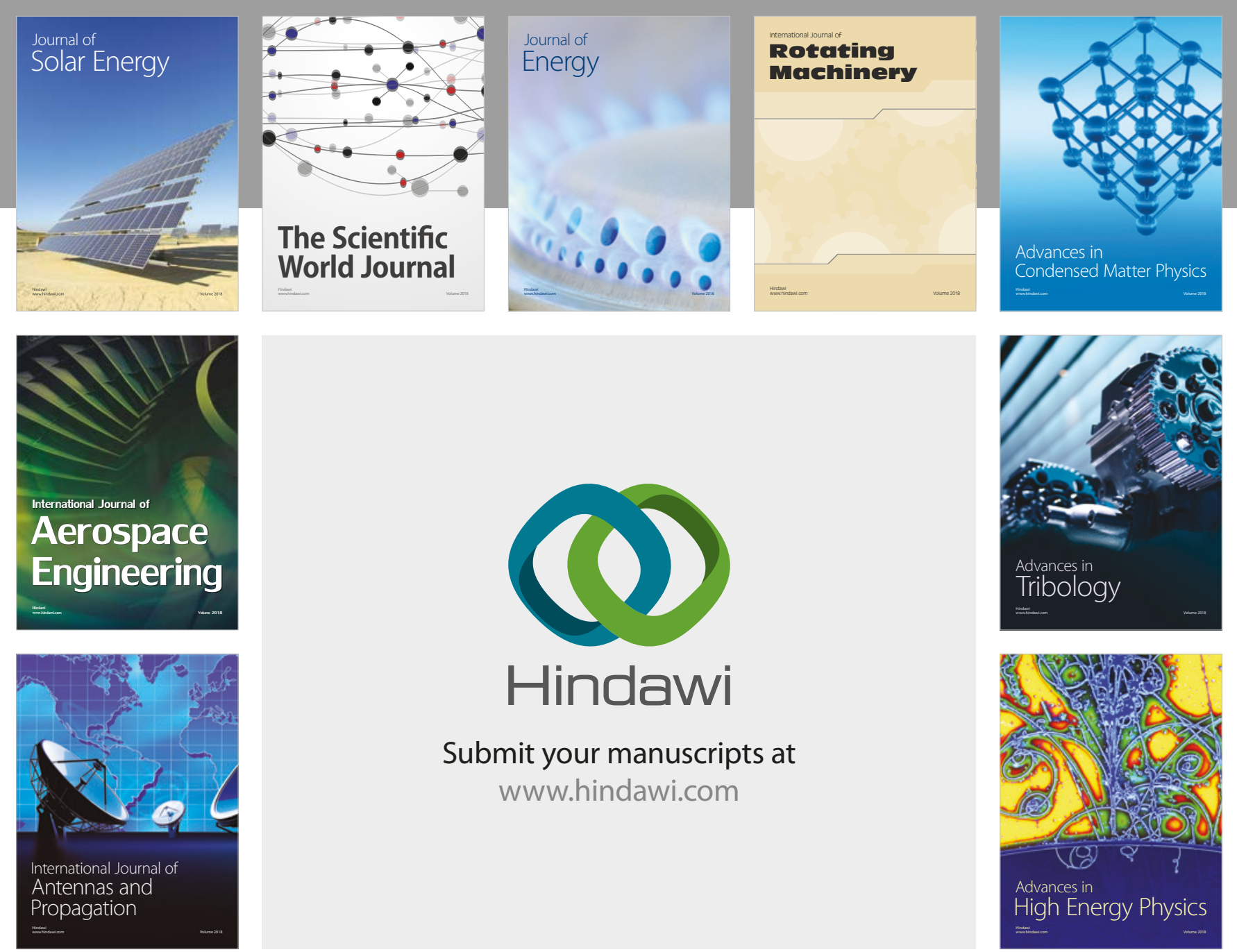

Submit your manuscripts at

www.hindawi.com
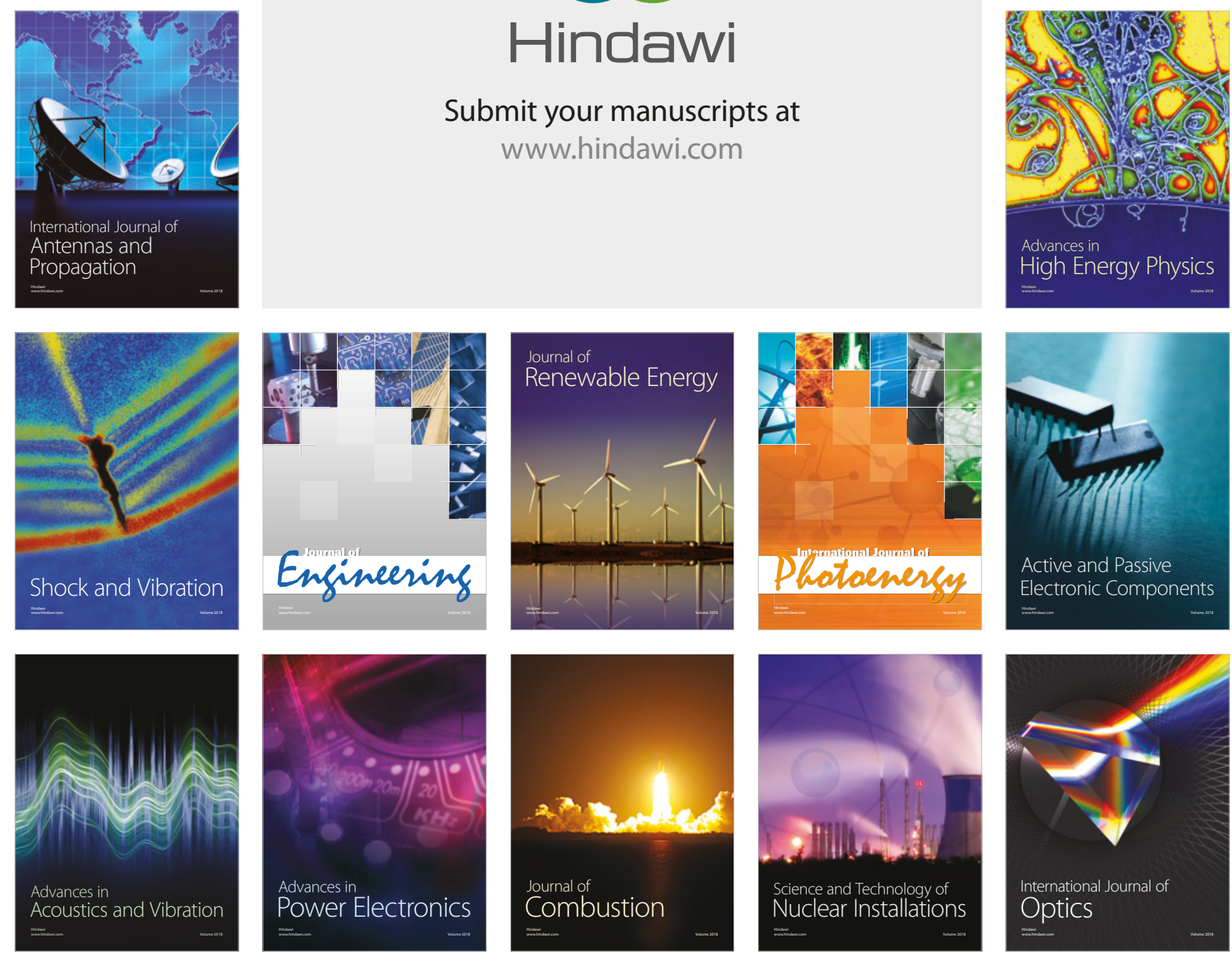